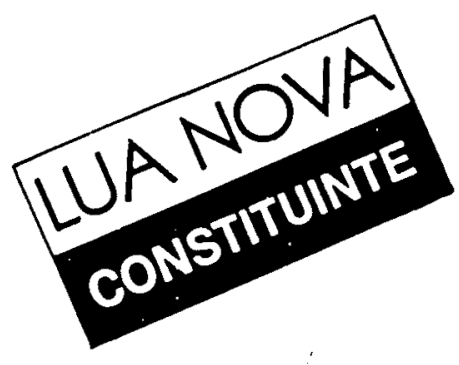

\section{A agrária}

José dos Reis Santos Filho

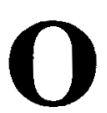

envolvimento da sociedade civil no debate sobre a Constituinte é real. No que se refere ao tema "questão agrária", ele tem-se manifestado de diversas formas. Seus antecedentes remontam à época de elaboração da Proposta do Primeiro Plano Nacional de Reforma Agrária, quando o Ministério da Reforma e do Desenvolvimento Agrário recebeu cerca de oitocentas sugestð̃es, muitas delas incidindo em modificaçð̄es reais nas bases legais de sustentação de uma política de transformação fundiária.

Hoje, esse envolvimento se manifesta através de propostas com origens bastante diferenciadas. Por um lado, instituiçð̃es de representação de classe como a Confederação Nacional dos trabalhadores na Agricultura (Contag) ou a Associação de Engenheiros-Agrônomos da Grande Dourados (Aegran). Por outro lado, entidades como a Igreja católica brasileira que, por meio da Conferência Nacional de Bispos do Brasil (CNBB), entrega aos constituintes uma contribuição para "uma nova ordem institucional". Vários partidos políticos, por sua vez, não deixaram de se manifestar. A julgar pelas informaçð̃es de que dispomos, não estão entre eles o Partido Democrático Social (PDS) e o Partido da Frente Litiral (PFL). Temos, também, neste acervo, iniciativas chegadas de juristas como a do professor Fábio Konder Comparato. Também estão presentes, na falta de nome melhor, "propostas de base", ou seja, de associações ou assembléias de moradores, de bairros ou de locais de trabalho. Poucas, mas significativas. Não pode ser esquecido, finalmente, o documento elaborado pela Comissão Provisória de Estudos Constitucionais, criada pela Presidência da República exclusivamente para este fim.

É notável a ausência de contribuições por parte das entidades ligadas à representação de empresários ou grandes proprietários rurais. Ao tão divulgado apoio às "candidaturas de classe" não corresponderam propostas públicas assinadas por organismos como a União Democrática Ruralista (UDR).

As propostas já conhecidas são bastante desiguais. Em várias, a questão agrária faz parte de um texto que, na verdade, pode ser considerado um anteprojeto de Constituição. São exemplos a do professor Comparato, a da Comissão Provisória, a do PC do B, a do PCB e da CNBB. 
Em outras, como a da Campanha Nacional pela Reforma Agrária, trata-se de uma intervenção exclusivamente voltada para esse fim.

A natureza das propostas determina, em grande medida, sua complexidade. Tratando-se de uma seção articulada como um todo, ela se prende a mecanismos de funcionamento do Estado, como é o caso trazido pelo PCB. Ali, o Plano Nacional de Reforma Agrária é parte do Plano Nacional de Desenvolvimento e é apresentado por um "Conselho de Ministros" ao Congresso, que o aprova.

O caráter da proposta determina também o quadro de valores que informa o conteúdo dos itens especificados. Sem pretender aprofundá-lo, o caso paradigmático é o da CNBB.
Ali, fala-se em "seres humanos" (em contraposição, por exemplo, a "individuos" ou a "trabalhadores", presentes em outros textos). E, como consequência, "os bens da terra têm destinação universal para a realização de todas as pessoas. A propriedade privada subordina-se a essa lei universal. Ela não se pode concentrar abusivamente nas mãos de poucos ou ser usada como instrumento de dominação e exploração de outros seres humanos. Ela só se justifica como garantia de liberdade, bem-estar pessoal, familiar e social"'.

Se pensarmos a partir de outro enfoque, talvez possamos arriscar a hipótese de que as experiências passadas - de desrespeito a direitos básicos - tenham levado à impressão de que o futuro legal garantido deve es-
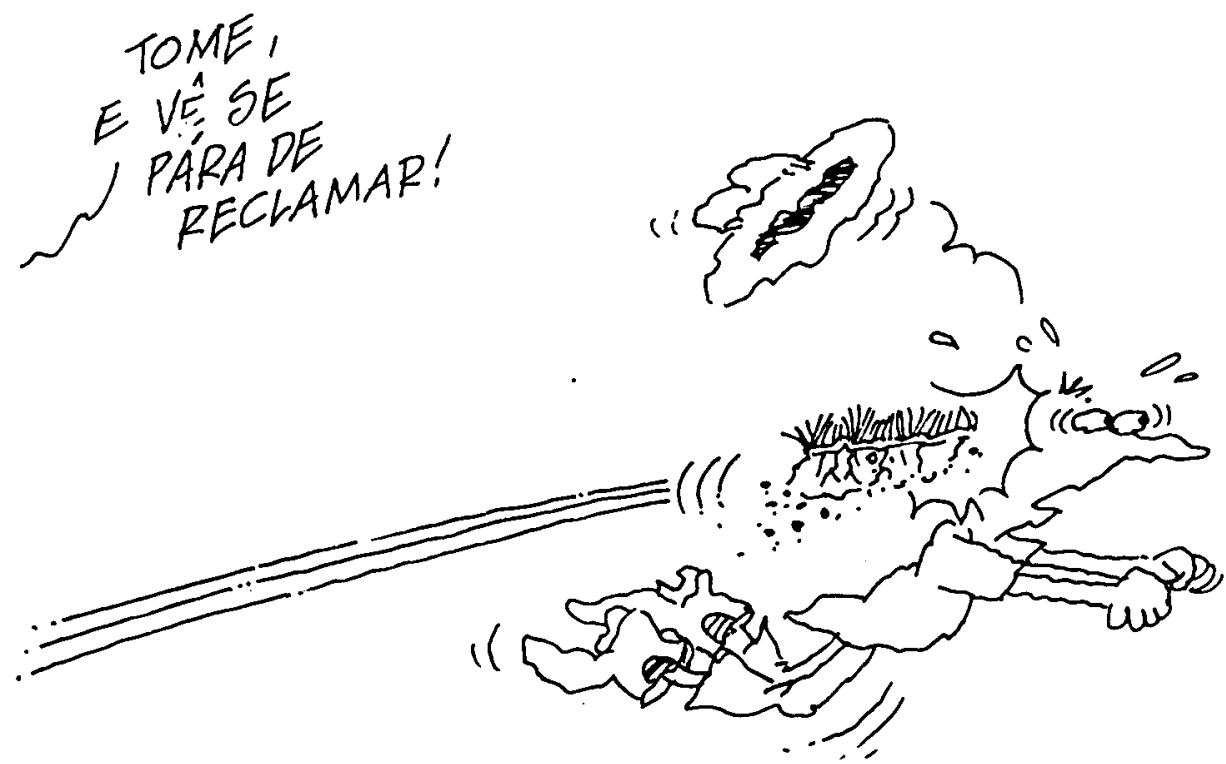
tar na Constituição. Essa compreensão talvez tenha contribuido para a ocorrência de longas e carregadas propostas.

Ainda que reconheçamos uma busca do abarcamento do conjunto de temas na grande maioria dos casos, o recurso não impediu a existência de situaçðes que podem se tornar problemas no futuro. Tomemos, por exemplo, a menção feita pelo PCB ao tratamento a ser dado na desapropriação: "assegura-se a expropriação dos meios de produção em abandono, nas condições fixadas por lei. $\mathrm{O}$ abandono injustificado não confere direito à indenização". Ao não abordar o tema desde o ponto de vista dos insiitutos de Direito Agrário Brasileiro já consolidados, ao adotar sem precisão maior a categoria do "abandono" como referência, a sugestão está muito provavelmente garantindo seu lugar nas discussōes interpretativas e nas jurisprudências dos tribunais.

No total, são quase trinta e cinco assuntos abordados pelo material analisado. São eles: 1) área reformada; 2) benfeitorias; 3) confisco; 4) cooperativas; 5) crédito rural; 6) desapropriação; 7) empresa rural; 8) estoque e terras; 9) estrangeiros; 10) extensão rural; 11) formas de exploração; 12) função social; 13) fundo de reforma agrária; 14) grilagem; 15) imóvel rural; 16) Imposto Territorial Urbano; 17) indenização; 18) latifúndio; 19) justiça agrária; 20) meio ambiente; 21) minifúndio; 22) módulo rural; 23) posse; 24) perda sumária da propriedade; 25) reforma agrária; 26) reintegração possessória; 27 ) reservas naturais; 28 ) superficie; 29) terras indígenas; 30) terras públicas; 31) titulação; 32) título da dívida pública.

É certo que alguns destes temas são dependentes, ou seja, completam ou são partes integrantes de outros. Não se pode falar de função social sem que toquemos em propriedade, por exemplo. Lembremos, no entanto, que, quanto mais clara e distinta estiver a expressão utilizada, quanto menos dúvidas e discussōes, maior a eficácia do dispositivo constitucional.

Há sugestões que têm sua explicação, muito provavelmente, na cultura política e nas relaçðos de poder estabelecidas no cotidiann da vida cumponesa. É o que ocorre com a mulher trabalhadora rural no momento em que reivindica, independentemente da situação, acesso à terra. Não são poucas as dificuldades impostas prlos organismos encarregados da administração da estrutura fundiária a essa aspiração. No limite, as condicionantes são tantas que o resultado é um dispositivo sugerido para a Constituição: segundo a Campanha Nacional pela Reforma Agrária, "deverá ser garantido o direito da mulher do trabalhador rural, viúva, concubina, separada, mãe solteira ou abandonada pelo marido, de ser beneficiária das terras distribuidas pela Reforma Agrária".

"Normalmente", a sugestão de um item com estas características poderia ser considerada redundante. $\mathrm{Na}$ medida em que a Lei Básica considera que todos são iguais perante a lei, desaparece qualquer razão para discriminaçð̋es não só contra a mulher, mas também contra qualquer um.

A consciência da gravidade dos 
problemas vividos pelos indigenas é transparente. Estão incluídos como questão na quase totalidade das propostas. $\mathrm{E}$ isso é tão mais importante na medida em que a questão indigena reverbera em um conjunto de outros interesses. Assim, é impossivel tratar de aspectos relativos à demarcação de terras sem enfrentar litígios com posseiros, mineradores. Mas também com as doutrinas sobre segurança nacional ainda vigentes nos meios militares.

A mesma preocupação se manifesta quanto ao meio ambiente. A dimensão ecológica aparece em v'arias das sugestōes como uma questão nacional. E certo que são abordados itens específicos. Os agrotóxicos surgem com atenção específica para alguns atores sociais. $O$ que merece destaque, no entanto, é a ênfase no tratamento do assunto como uma questão por sobre a qual não se pode passar. A Comissão Provisória de Assuntos Institucionais expressa essa tendência: "o planejamento harmonizará o desenvolvimento econômico com a preservação do equilíbrio e com a qualidade do meio ambiente".

Já dissemos que são muitos os temas abordados pelas propostas. Entre eles aparecem alguns que merecem destaque todo especial. São, certamente, o núcleo a partir do qual se institui o tratamento da questão agrária, desde o ponto de vista legal no Brasil de hoje. São eles: 1) propriedade; 2) função social; 3) módulo; 4) desapropriação, confisco, perda sumária da propriedade; 5) indenização; 6) tributação; 7) terras indí- genas; 8) meio ambiente; 9) titulação; 10) financiamento; 11) cooperativas; 12 ) justiça agrária.

A julgar pelos dados disponíveis, tanto por incidência como pela intensidade dos debates, são estes os doze temas de maior importância. Não são poucos, é claro. Mas são o suficiente para tornar decisiva a discussão. Afinal, entre eles está o assunto que se transforma, progressivamente, no grande "divisor de águas". A propriedade separa, de fato, os grandes campos. Para alguns, "propriedade sem penduricalhos". De fato, dar as costas a uma tradição jusagrarista brasileira que se desenvolve há algumas décadas. Para outros, dar continuidade a esta tradiçāo, aprofundando e superando as noções atuais que giram em torno da função social da propriedade.

Reparemos, no entanto, que nem tudo é oito ou oitenta neste debate. Ainda que a propriedade e sua qualific ação separe campos, no interior destes campos encontramos diferenciaçס̃es nada desprezíveis. Os extremos, se não forem explicados através das características que desenham seu conteúdo, tendem a confundir, mais que explicar. E, nesse sentido, é imprescindivel analisar o conjunto de propostas, indicando não apenas seus grandes eixos, mas principalmente buscando identificar: a) as concepçőes que informam cada uma delas; b) as tradiçðos em que se inserem ou com que rompem individualmente; c) as consequiências da adoção destas propostas. 